\title{
Biological Characteristics and Germination Conditions of Gentianae macrophylla Seeds under Different Storage and Seed Treatments
}

\author{
Yanfang Sun ${ }^{1,3}$, Wan Wang ${ }^{2}$, Juanfang $\mathrm{Xie}^{4}$ and Zongsuo Liang ${ }^{1,2^{*}}$ \\ ${ }^{1}$ Key Laboratory of plant Secondary Metabolism and Regulation of Zhejiang Province, College of Life Sciences, Zhejiang Sci- \\ Tech University, Hangzhou 310018, China \\ ${ }^{2}$ State and Local Joint Research Center of TCM Fingerprinting and NP Library, College of Life Sciences, Northwest A\&F \\ University, Yangling 712100 China \\ ${ }^{3}$ Institute of Pharmacy and Molecular Biotechnology, Heidelberg University, Im Neuenheimer Feld 364, 69120 Heidelberg, \\ Germany \\ ${ }^{4}$ Longde northwest medicinal materials technology Co, Ltd., Ningxia 756300, China \\ *For correspondence: katherineyfs@sina.com; liangzs@ms.iswc.ac.cn
}

\begin{abstract}
This study investigated the biological characteristics of large-leaved gentian seeds and the effects of germination temperature, illumination, pretreatment, storage temperature and time on the seed germination by calculating the seed germination rate. The results showed that most of gentian seeds were oblong and brown, and its 1000 seed weight was $0.300 \pm 0.0004 \mathrm{~g}$. The seed water absorption presented "S"-shaped curve with seed soaking time, including sharp, stable and saturated water absorption stages. The optimum germination temperature of large-leaved gentian seeds was $25^{\circ} \mathrm{C}$ and the seeds were more conducive to germinate under dark condition than under light condition. Gibberellins soaking could significantly improve the seed germination rate; low temperature storage could prolong the vitality of gentian seeds. In the actual production, the germination rate of gentian seeds can be improved by gibberellins seed dressing firstly and then sowing method, in order to shorten the germination period. This study can provide a good basis for identifying the gentian seeds and large-scale breeding and cultivation. C 2017 Friends Science Publishers
\end{abstract}

Keywords: Medicinal and aromatic plant; Gentianae macrophylla; Seed germination; Biological characteristics

\section{Introduction}

The large-leaved Gentiana macrophylla Pall. belongs to a medicinal and aromatic plant of gentianaceae, Gentiana spenceri, Sect. Cruciata Gaudin group (Li et al., 2002). It had the functions of dispelling wind and eliminating dampness, activating blood and dissolving stasis, antiinfluenza virus and treating rheumatic pain etc (Skryzypczak et al., 1993; Yu et al., 2004). In recent years, rapidly increasing demand and excessive excavation results in less large-leaved gentian wild resources (Ma, 2005), therefore it has been listed as one of the nationally particularly protected wild herbs. The artificially cultivated large-leaved gentian was mostly through seed propagation (Cao et al., 2005), but its seeds are very small and their morphological characteristics are not easily observed under naked eye. Therefore, mixed collection is often used; the natural life of large-leaved gentian seeds is very short, only one year. Importantly, seed germination speed is slow and germination rate is only $20 \%$ every year (Niu et al., 2014). Therefore, it is of important application value for guiding the production to study the basic characteristics and germination influence factors of large-leaved gentian seeds. In recent years, there are many researches on the effective components and pharmacology (Zhao et al., 2010), but rare report on the morphological characteristics and germination conditions of large-leaved gentian seeds. The purpose of this study was to investigate the basic biological characteristics of large-leaved gentian seeds and the effects of germination temperature, illumination, ultrasound, gibberellins, polyethylene glycol (PEG-4000) treatment, storage temperature and time on seed germination, to provide the theoretical and technical bases for large-leaved gentian seeds identification and large-scale cultivation.

\section{Materials and Methods}

\section{The Biological Characteristics of Large-leaved Gentian} Seeds

The tested seeds were collected from medicinal large-leaved gentian base during October, 2014 in Longde city of Ningxia $(106 \cdot 11 \mathrm{~N}-35 \cdot 63 \mathrm{E})$. The large-leaved gentian seeds after natural drying were collected in very year, 
ultrasonically cleaned with ultrapure water, to remove debris on the seeds surface. The uniform and full seeds were screened with the seed sieve $(0.42 \mathrm{~mm})$, soaked using $75 \%$ alcohol for $30 \mathrm{~s}$, then rinsed using sterilized water for three times. The tests were conducted as follows:

The color and shape were observed under the microscope (NIKON Eclipse E200). The length and width of seeds were measured using the digital electronic vernier caliper.

The seeds were pasted on the conducting resin in the scanning electron microscope sample platform, and the gold film vacuum evaporating was performed. Finally, the sample was moved into the electron microscope room and the ultrastructure of large-leaved gentian seeds was observed under the accelerating voltage.

\section{Determination of 1000-seed Weight and Vitality of Gentian Seeds}

Thousand seeds were randomly weighed and repeated for 3 times and averaged. Triphenyltetrazolium chloride (TTC) quantitative method was used to evaluate the vigour of seed (Holubowicz et al., 2001).

\section{Water Absorption Rate of Seeds}

$2.0 \mathrm{~g}$ seeds were accurately weighed using the electronic scale $(1 / 10000)$, placed into a $50 \mathrm{~mL}$ beaker, soaked in the distilled water at $20^{\circ} \mathrm{C}$ thermostat water bath. The seeds were removed every $2 \mathrm{~h}$, dried and accurately weighed. The seed water absorption was calculated and repeated for three times.

The seed water absorption rate $=[($ seed quality after water absorption - seed quality before water absorption)/seed quality after water absorption] $\times 100 \%$.

\section{Seed Germination Test}

For germination, 4 temperature gradients: 15, 20, 25 and $30^{\circ} \mathrm{C}$ were cultured in the constant temperature incubator.

For germination, seeds was put into the dish in the artificial climate incubator, and light intensity was 1500 LX for $12 \mathrm{~h}$ /day until the end of seed germination. Under the dark condition for seed germination was set: the dish with wrapping black paper put in the dark and constant temperature environment for sprouting, repeated for three times according to the above conditions.

\section{Effect of Pretreatment on Seed Germination Rate}

The seeds were treated using the ultrasonoscope (KH-250 $\mathrm{DH}), 40 \mathrm{KHz}$ for $60 \mathrm{~min}$ and then soaked using the distilled water.

The different concentration gradients of $\mathrm{GA}_{3}$ solution $\left(100,300,500,700\right.$ and $\left.900 \mathrm{mg} \cdot \mathrm{L}^{-1}\right)$ and three different concentration gradients of PEG-4000 solution (10\%, 20\% and $30 \%$ ) were developed.
The control group was set for each treatment group. The seeds were rinsed using the distilled water, placed in the double-layer filter paper petri dish with 50 seeds in each petri dish. The treatment was repeated for three times, cultured in the constant temperature incubator $\left(25^{\circ} \mathrm{C}\right)$, maintained moist and the daily germination seed number was recorded. The germination energy (GE) was determined at the $15^{\text {th }}$ day and the germination rate $(G R)$ calculated on the $23^{\text {th }}$ day (Gesch et al., 2016).

$G E=$ (germination number in the $15 \mathrm{~d} /$ total number of the tested seeds) $\times 100 \%$.

$G R=$ (germination number in the $23 \mathrm{~d} /$ total number of the tested seeds) $\times 100 \%$.

\section{Effects of Storage Temperature and Time on Seed Germination Rate}

The full and uniform large-leaved gentian seeds were selected and stored at 25,4 and $-20^{\circ} \mathrm{C}$ respectively. The storage time was $0.5,1,7$ and 12 months respectively.

\section{Effects of $\mathrm{GA}_{3}$ Treatment on Seed Germination Rate using the Different Storage Methods}

The seeds after storage for $0.5,1,7$ and 12 months at $4^{\circ} \mathrm{C}$ were taken, surface sterilized at first, then soaked in 500 $\mathrm{mg} / \mathrm{L} \mathrm{GA}_{3}$ for $24 \mathrm{~h}$.

The seeds were paved in the petri dish with the filter paper after soaking seeds, 50 seeds in each petri dish, repeated for three times, cultured in the constant temperature incubator.

\section{Data Analysis}

All assays were carried out three times. The data are expressed as mean \pm standard deviation. Statistical analysis was performed by one-way analysis of variance (ANOVA) using GraphPad Prism software (GraphPad Software, Inc., CA, USA). $P$-value less than 0.05 was considered significant. Graphs were drawn using SigmaPlot 13.0 software.

\section{Results}

\section{Seed Morphology Observation}

The large-leaved gentian seeds were brown, red brown or light brown, oblong or narrow oblong and glossy (Fig. 1). Scanning electron microscope results showed that the full seed epidermis was strip-type reticulate ornamentation. The reticulation protruded into the spine. The internal spines were depressed into a reticulation. The width and depth of reticulation were different, umbilici located in the tip of seed base, and subsidence of suborbicular type. The wizened seed epidermis of large-leaved gentian was depressed, small volume and the umbilici irregularly wizened (Fig. 2). 


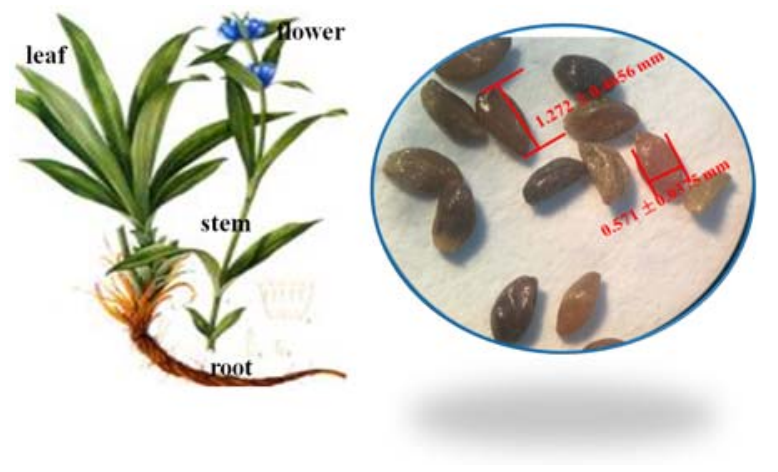

Fig. 1: The morphological characteristics of $G$. macrophylla seeds under anatomical lens $(\times 300)$
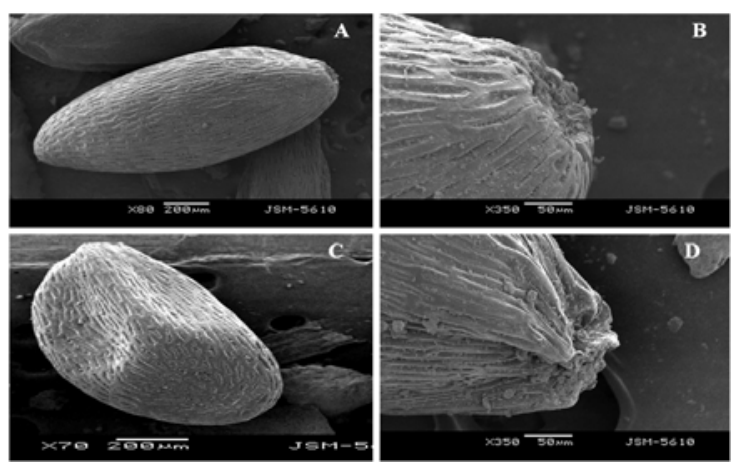

Fig. 2: The ultrastructure of seed and hilum of $G$. macrophylla by scanning electron microscopy: (A) full

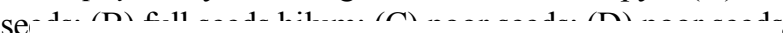

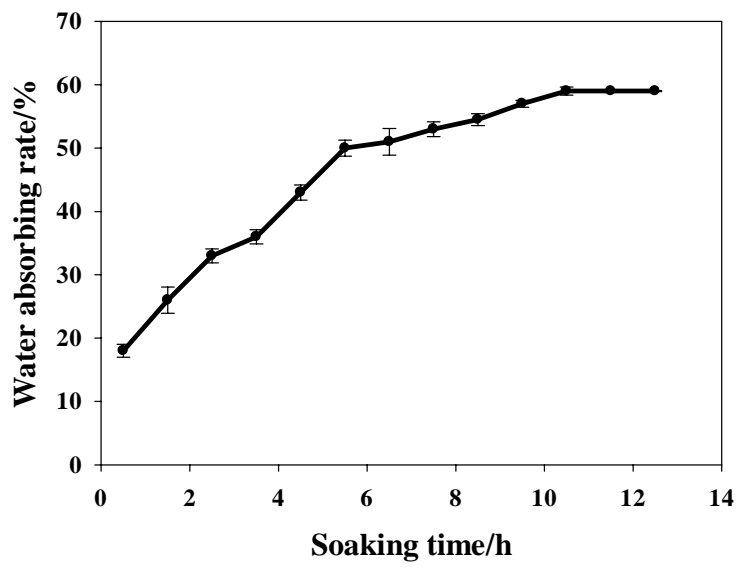

Fig. 3: The changes of seed water absorbing rate of $G$. macrophylla seeds under different soaking time

\section{Thousand Seed Weight and Vitality of Large-leaved Gentian Seeds}

The length of large-leaved gentian seeds was $1.272 \pm 0.4656$ $\mathrm{mm}$, the width of $0.571 \pm 0.0375 \mathrm{~mm}$ with length-width ratio of $2.228 \mathrm{~mm}$, and the 1000 -seed weight of $0.300 \pm 0.0004 \mathrm{~g}$. TTC assay result showed that the vitality of large-leaved

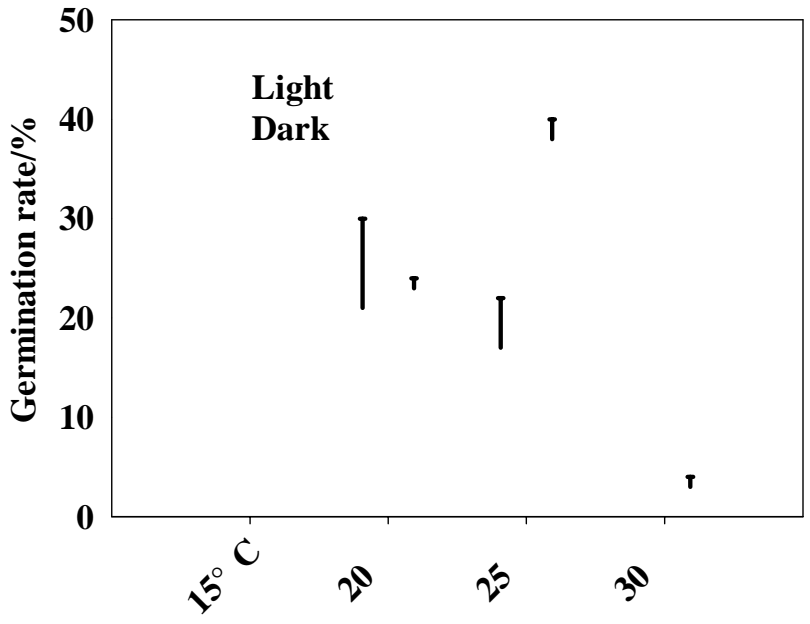

Fig. 4: Different temperature and light conditions on the influence of germination rate of $G$. macrophylla seeds

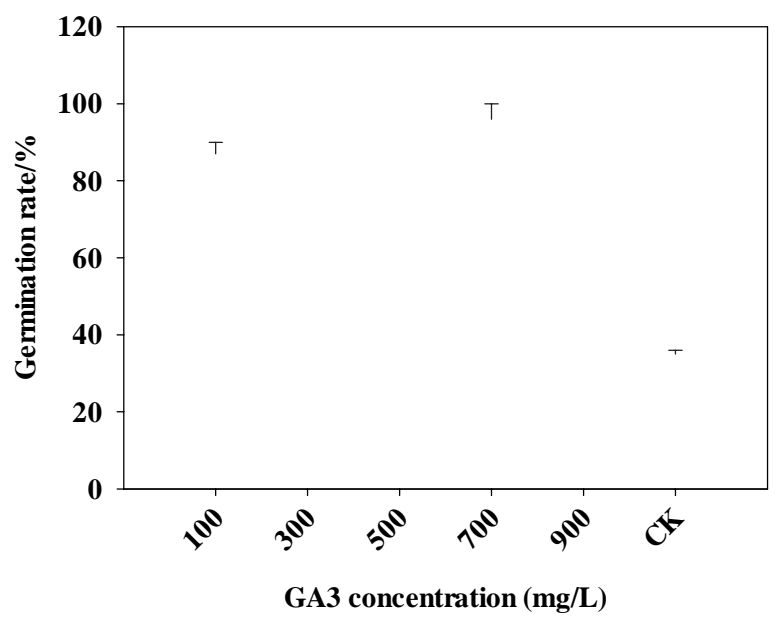

Fig. 5: Effects of $\mathrm{GA}_{3}$ concentration on the influence of germination rate of $G$. macrophylla seeds

gentian seeds was $94.3 \%$ with the seed germination rate of $17 \%$ under the condition of constant temperature, suggesting the seeds in dormant state.

\section{Water Absorption Law of Large-leaved Gentian Seeds}

The water absorption was calculated according to the quality change of large-leaved gentian seeds during the water absorption process. Then the water absorption curve was drawn according to its rate. As shown in Fig. 3, the water absorption rate presented as approximate "S-shaped" curve with the seed soaking time. The seeds immediately imbibed after soaking, the water absorption was rapidest in $3 \mathrm{~h}$, and its rate reached $34.40 \%$. This period was called as the rapid water absorption period, the imbibition peak finished after soaking for $10 \mathrm{~h}$. The seeds went into the stable water absorption period and rate reached $5.96 \%$. The seeds went into the water absorption saturation period after 


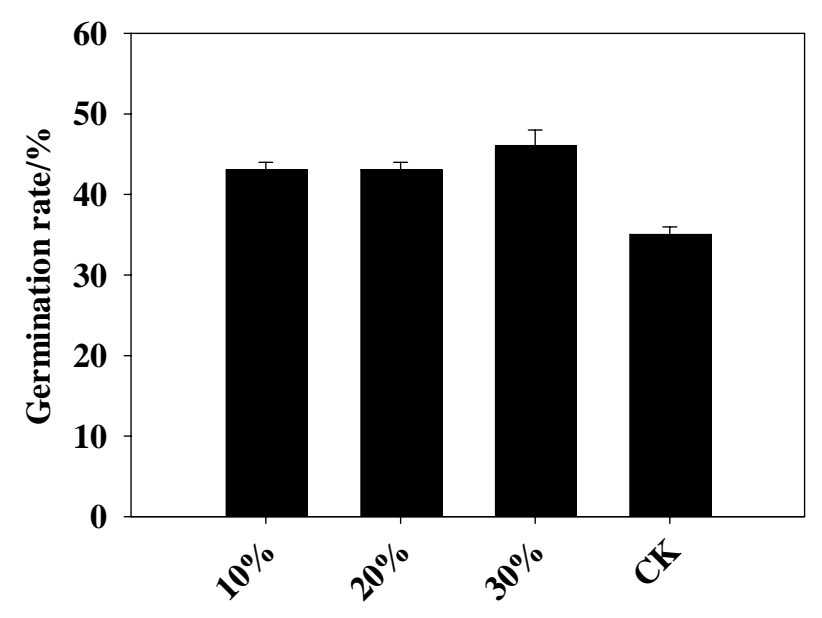

PEG-4000 concentration

Fig. 6: Effects of PEG-4000 concentration on the influence of germination rate of G. macrophylla Pall. Seeds

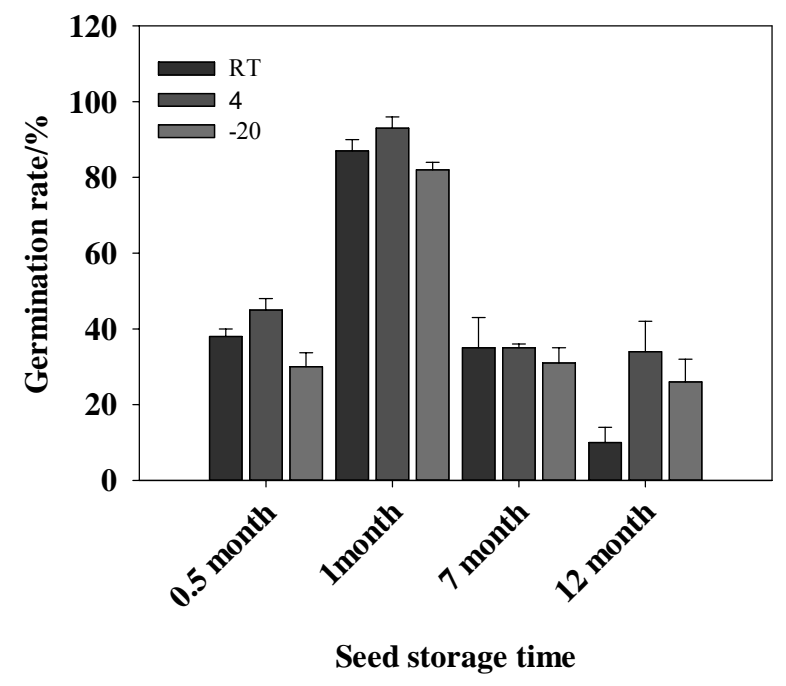

Fig. 7: Effects of seed storage temperature and time on the influence of germination rate of $G$. macrophylla seeds

soaking for $11 \mathrm{~h}$, and its rate was maintained to be $60.40 \%$. Therefore, in the actual production, the best soaking time of large-leaved gentian seeds was within $12 \mathrm{~h}$.

\section{Effect of Temperature on Seed Germination of Large- leaved Gentian}

The results showed that the large-leaved gentian seeds did not germinate under light and dark conditions at $15^{\circ} \mathrm{C}$. Under light condition at $30^{\circ} \mathrm{C}$ and the germination rate was only $2 \%$ under dark condition. The seeds began to germinate under light condition at $20^{\circ} \mathrm{C}$ at $9^{\text {th }} \mathrm{d}$. The germination velocity was uniform and the germination rate reached $21 \%$ at $23 \mathrm{~d}$; while seeds began to germinate under dark condition at $8^{\text {th }} \mathrm{d}$. The germination peak was from $9^{\text {th }}$

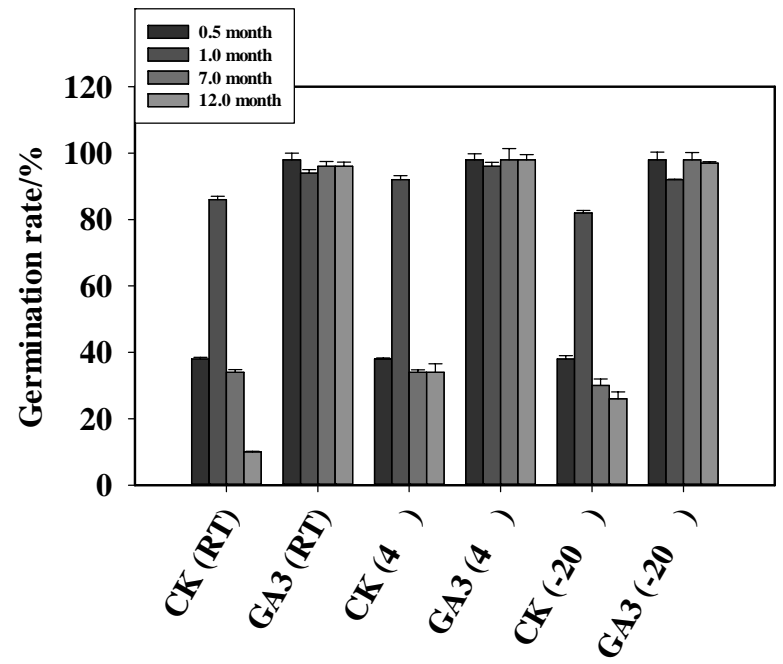

Fig. 8: Effects of $\mathrm{GA}_{3}$ on germination of $G$. macrophylla Pall. seeds of different storage temperature and time

to $13^{\text {th }} \mathrm{d}$. Later, the germination rate gradually decreased and reached $23 \%$ at $23^{\text {th }} \mathrm{d}$. The results showed that the germination time of seeds under the dark condition at $20^{\circ} \mathrm{C}$ was earlier than of the light condition (Fig. 4), the germination rate slightly higher, indicating that the dark condition showing it more in favor for the seed germination.

The seeds began to germinate under $25^{\circ} \mathrm{C}$ light condition at $6^{\text {th }} \mathrm{d}$ and germination rate of uniform-velocity increased. The seeds did not grow at $20^{\text {th }} \mathrm{d}$ and the germination rate reached $17 \%$, and lower than at $25^{\circ} \mathrm{C}$ light condition. The seeds began to germinate at $6^{\text {th }} \mathrm{d}$ and the germination peak was from $9^{\text {th }}$ to $17^{\text {th }} \mathrm{d}$. Later, the germination rate was gradually decreased and reached $38 \%$ at $23^{\text {th }} \mathrm{d}$ (Fig. 4). The results showed that the germination time of seeds under $25^{\circ} \mathrm{C}$ dark condition was earlier than of light condition and the germination rate slightly higher twice of light condition.

The germination cycle of large-leaved gentian seeds was long but the germination slow, began at $6^{\text {th }} \mathrm{d}$ as earliest and stopped at $20^{\text {th }} \mathrm{d}$. Overall, the seed germination rate under dark condition was higher than under light and more conducive to the germination of large-leaved gentian seeds. Statistical analysis showed that the germination rate of largeleaved gentian seeds was not significant at $20^{\circ} \mathrm{C}$ light, $20^{\circ} \mathrm{C}$ dark and $25^{\circ} \mathrm{C}$ light conditions. But the seed germination rate at $25^{\circ} \mathrm{C}$ dark condition was significantly higher than other conditions $(P<0.05)$. Therefore, the optimum condition of large-leaved gentian seeds was $25^{\circ} \mathrm{C}$ under dark.

\section{Effect of Ultrasonic Treatment on Seeds Germination}

Ultrasonic pretreatment resulted in earlier seed germination time and the germination rate reached $41 \%$. While the seeds stopped germination at $21^{\text {th }} \mathrm{d}$ in the control group and the germination rate was $35 \%$. The statistical analysis showed that the germination rate of large-leaved gentian seeds 
showed significant difference after ultrasonic pretreatment compared with the control group $(P \leq 0.05)$, suggesting that the ultrasonic pretreatment had certain influence on largeleaved gentian seeds.

\section{Effect of Gibberellins on Seeds Germination}

The large-leaved gentian seeds in the control group began to germinate from $9^{\text {th }} \mathrm{d}$ and stopped germination at $21^{\text {th }} \mathrm{d}$ with germination rate of $35 \%$ (Fig. 5). The germination rate of large-leaved gentian seeds were significantly improved after soaking with different concentrations of gibberellins compared with the control group. The seed germination cycle was shortened with more regular germination. The seeds began to germinate from $6^{\text {th }} \mathrm{d}$ after pretreatment with $\mathrm{GA}_{3}$ and stopped at the $22^{\text {th }}, 21^{\text {th }}, 22^{\text {th }}, 20^{\text {th }}$ and $17^{\text {th }} \mathrm{d}$ after pretreatment with $100,300,500,700,900 \mathrm{mg} \cdot \mathrm{L}^{-1} \mathrm{GA}_{3}$ solution respectively and the germination rates reached to $86,98,98,96$ and $98 \%$, respectively. The germination cycle was shortest after pretreatment with $900 \mathrm{mg} \cdot \mathrm{L}^{-1} \quad \mathrm{GA}_{3}$ compared with control group and it, shortened for $4 \mathrm{~d}$, the germination energy increased by $79 \%$ and germination rate by $64 \%$. The significant analysis showed that the germination rate after soaking with five concentrations of gibberellin solution was significantly higher than soaked with the distilled water. After soaking with different concentration gradients: $300,500,700,900 \mathrm{mg} \cdot \mathrm{L}^{-1} \mathrm{GA}_{3}$, the germination rate was significantly higher than of $100 \mathrm{mg} \cdot \mathrm{L}^{-1}$ $\mathrm{GA}_{3}(P \leq 0.05)$, while the germination rates showed no significant difference after soaking seeds between 300,500 , 700 and $900 \mathrm{mg} \cdot \mathrm{L}^{-1} \mathrm{GA}_{3}$ solution (Fig. 5).

\section{Effect of Polyethylene Glycol (PEG-4000) on Seeds Germination}

In the Fig. 6, the seeds began to germinate in the control group at $9^{\text {th }} \mathrm{d}$ and stopped at $21^{\text {th }} \mathrm{d}$ with germination rate of $35 \%$. The large-leaved gentian seeds began to germinate after soaking seeds with $10 \%$ PEG-4000 solution at $8^{\text {th }} \mathrm{d}$ and the germination rate reached the maximum value of $43 \%$. The large-leaved gentian seeds began to germinate after soaking seeds with $20 \%$ PEG-4000 solution in $7^{\text {th }} d$ and stopped at $22^{\text {th }} \mathrm{d}$ with germination rate of $43 \%$. The large-leaved gentian seeds began to germinate after soaking seeds with $30 \%$ PEG-4000 solution at the $6^{\text {th }} \mathrm{d}$. The germination rate reached the maximum value of $45 \%$. The germination energy after soaking seeds with 3 concentrations of PEG-4000 was significantly improved compared with the control group. The germination rate after seeds soaking with $30 \%$ PEG-4000 was significantly higher than $10 \%$ and $20 \%$ PEG-4000 solution $(P \leq 0.05)$, but the germination rates showed no significant difference between after seeds soaking with $10 \%$ and $20 \%$ PEG- 4000 solution.

For all, among the ultrasonic pretreatment, $\mathrm{GA}_{3}$ and PEG-4000 soaking, the effect of $\mathrm{GA}_{3}$ solution on the germination rate was maximum. $900 \mathrm{mg} \cdot \mathrm{L}^{-1} \mathrm{GA}_{3}$ solution increased the germination rate from $34 \%$ to $98 \%$.

\section{Effects of Storage Temperature and Storage Time on Seeds Germination}

The seeds began to germinate at $6^{\text {th }}$ day, stopped germination at $22^{\text {th }} \mathrm{d}$ and the germination rate was $38 \%$. The same batch of seeds was divided into 3 pieces, sealed and stored at room temperature, $4^{\circ} \mathrm{C}$ and $-20^{\circ} \mathrm{C}$ respectively (Fig. 7). After storage for a week, the stored seeds under three conditions were taken for the second germination test. After storage at room temperature for a month, the seeds began to germinate at the $8^{\text {th }} \mathrm{d}$ and showed higher germination rate, suggesting the seeds vitality was increased, the final germination rate reached $87 \%$, and it significantly improved. After storage at room temperature for 7 months, the germination time was postponed to $10^{\text {th }} \mathrm{d}$ and the germination rate was lower compared with before the storage. After stored at room temperature for 12 months, the germination time was postponed to $11^{\text {th }} \mathrm{d}$. The final germination rate was only $10 \%$.

The germination rate of large-leaved gentian seeds stored at $4^{\circ} \mathrm{C}$ reached $93 \%$ a month later, which increased by $55 \%$ compared with before storage, the germination peak was from $10^{\text {th }} \mathrm{d}$ to $14^{\text {th }} \mathrm{d}$. After stored for 7 months, the germination rate reduced to $35 \%$ and after stored for 12 months, it was $34 \%$. The germination rate of large-leaved gentian seeds at $-20^{\circ} \mathrm{C}$ reached $82 \%$ a month later, which increased by $44 \%$ compared with before storage. After stored for 7 months, the final germination rate was $31 \%$, lower than before storage $(P \leq 0.05)$. After stored for 12 months, the germination rate continued to decrease to $26 \%$. The germination rate of the newly harvested large-leaved gentian seeds was lower.

After storage for a month, the germination rate of large-leaved gentian seeds was significantly increased. The germination rates of large-leaved gentian seeds reached $80 \%$ by three kinds of storage methods. Statistical analysis showed that the germination rate of large-leaved gentian seeds at $4^{\circ} \mathrm{C}$ was significantly higher than of room temperature and $-20^{\circ} \mathrm{C}$. Hereafter, the germination rate of large-leaved gentian seeds rapidly declined. After storage for 7 months, the seed germination rate was decreased to about $30 \%$. The germination rates showed no significant difference among three kinds of storage methods. After storage for 12 months, the seed germination rate at room temperature was only $10 \%$. The germination rates at $4^{\circ} \mathrm{C}$ and $-20^{\circ} \mathrm{C}$ were 34 and $26 \%$, which were significantly higher than at room temperature.

\section{Effects of Gibberellins Treatment on Seeds Germination Rate with Different Storage Temperatures and Different Time}

The effects of $\mathrm{GA}_{3}$ on large-leaved gentian seeds with different storage temperatures and time were investigated 
after seed soaking with $500 \mathrm{mg} \cdot \mathrm{L}^{-1} \mathrm{GA} 3$ solution. $\mathrm{GA}_{3}$ could enable the seed germination rates reach above $92 \%$ at room temperature, $4^{\circ} \mathrm{C}$ and $-20^{\circ} \mathrm{C}$ in $0.5,1,7,12$ months before storage (Fig. 8). In addition, the final germination time showed that $\mathrm{GA}_{3}$ could greatly shorten the large-leaved gentian seed germination cycle and improved the seed germination uniformity.

\section{Discussion}

The external morphology and surface ultrastructure of largeleaved gentian seeds were observed and compared. The micromorphology of full seeds was different from wizened seeds. The fullness and umbilici morphology were the prerequisite to ensure the seed germination, so the morphological characteristics and scanning electron microscope observation of large-leaved gentian seeds could be taken as one of the seed classification that provided new evidence for seed identification and planting.

The water absorption of seeds reflected the permeability of seed coat. The seeds with good water absorption could quickly absorb moisture in the environment, which was conducive to the seed germination. In this study, after the tested large-leaved gentian seeds were soaked for $11 \mathrm{~h}$, the seeds were saturated and water absorption rate was $60.4 \%$, suggesting that the permeability of large-leaved gentian seed coat was good, the germination of large-leaved gentian seeds would not be affected.

The temperature and light were essential for the germination of seeds (Torra et al., 2015). The temperature is a very important environmental factor to mediate the seed germination. The seed can judge the season change and microenvironment difference and choose the appropriate opportunity to germinate by perceiving high and low temperature or by temperature change (Kaldy et al., 2015). The higher environment temperature can deepen the seed dormancy, while the low temperature has a very important effect on the seed breaking dormancy (El Harfi et al., 2016). Some plants seeds germinate at a specific temperature. While some plant seeds germination needs a temperaturechanging process. Meanwhile, the temperature is also essential for the seed germination. The suitable temperature can increase the seed embryo metabolism, strengthen the respiratory action, increase the enzyme activity and accelerate the seed germination. The large-leaved gentian seeds germinate at the intermediate temperature. The optimal germination temperature was $20 \sim 25^{\circ} \mathrm{C}$, and the lowest germination temperature was $8 \sim 10^{\circ} \mathrm{C}$. The temperature more than $30^{\circ} \mathrm{C}$ could significantly inhibit the germination of large-leaved gentian. The study found that the germination rate of large-leaved gentian seeds reached $38 \%$ at $25^{\circ} \mathrm{C}$, which was suitable for seed germination. It was reported that large-leaved gentian contained the substance which could inhibit seed germination. The substance was known as endogenous inhibitor and was one of the main factors to cause large-leaved gentian seed dormancy.

Light is one of the most important environmental factors in plant life. Previous studies have confirmed that the seeds depend on phytochrome, perceiving the surrounding environment and respond through the optical signal pathway (Dooley et al., 2013). In this experiment, the germination rate of large-leaved gentian seeds under dark condition was higher than under light condition. Therefore, the casing soil should be paid attention when sowing seeds and the straw should be covered, so as to improve the germination rate.

At present, all kinds of methods are tried to improve the seed germination rate in production (Darrudi et al., 2015). Certain artificial processing can improve the seed germination rate. The common methods include ultrasound treatment, chemical reagent, stripping the seed coat and other methods. The ultrasonic wave can induce the synthesis of macromolecules in the living beings and improve the activity of enzymes, which can positively promote the seed germination. The large-leaved gentian seeds were treated with the ultrasound in this study, which could significantly increase the germination rate. The seeds were treated with exogenous hormone gibberellin, the seed dormancy could be released, the germination could be promoted (Bishnoi, 2010; Nabaei et al., 2011), the process involved a serial of complex interacted internal regulation and control. The large-leaved gentian seeds were treated with different concentrations of gibberellins (Wang et al., 2016). The results showed that the effect of $900 \mathrm{mg} \cdot \mathrm{L}^{-1} \mathrm{GA}_{3}$ solution on large-leaved gentian seeds was maximum, the germination cycle was shortest, and the germination rate increased to $98 \%$. This might because that $\mathrm{GA}_{3}$ could regulate largeleaved gentian seed dormancy, relieve the seed dormancy and promote the germination (Seo et al., 2016). PEG-4000 can repair the membrane system by controlling the water, so as to win enough time, alleviate the damage of the membrane, thus increasing the seed germination rate. The study found that the germination rate of large-leaved gentian seeds after PEG-4000 soaking was significantly higher than of the control group.

\section{Conclusion}

Seed filling is a key factor of the germination of largeleaved gentian seeds. The optimum germination temperature of large-leaved gentian seeds is $25^{\circ} \mathrm{C}$. The dark condition is more conducive to the germination of large-leaved gentian seeds compared with under light condition. Gibberellins soaking can significantly improve the germination energy and germination rate of large-leaved gentians. The life of large-leaved gentian seeds is about 1 year under natural condition. Low temperature storage can prolong the vitality of large-leaved gentian seeds. In the actual production, the germination rate and uniformity of large-leaved gentian seeds can be improved by gibberellins seed dressing method at first and then sowing, so as to shorten the germination cycle. 


\section{Acknowledgments}

This work was supported by the grants from the National Science Council (No. 81373908) and the Major Industrial Cluster Project in Shaan'xi Province, China (No. 2012KTCL02-07).

\section{References}

Bishnoi, U.R., 2010. Methods to improve seed germination of purple coneflower (Echinacea purpurea (L.) Moench). Agric. Biol. J. North Amer., 1: 185-188

Cao, J.P., X. Liu, J.G. Hao and X.Q. Zhang, 2005. Tissue culture and plantlet regeneration of Gentiana macrophylla. Acta Bot. Bor. Occid. Sin., 25: 1101-1106

Dooley, F.D., S. Wyllie-Echeverria and E.V. Volkenburgh, 2013. Long-term seed storage and viability of Zostera marina. Aquat. Bot., 111: 130-134

Darrudi, R., M.R. Hassandokht and V. Nazeri, 2015. Effects of moist stratification, $\mathrm{GA}_{3}$ and seed age on seed germination of Rheum khorasanicum, B. Baradaran and A. Jafari. J. Appl. Res. Med. Aromatic Plants, 2: 168-173

El Harfi, M., H. Hanine, H. Rizki, H. Latrache and A. Nabloussi, 2016. Effect of drought and salt stress on germination and early seedling growth of different color-seeds of sesame (Sesamum indicum). Int. J. Agric. Biol., 18: 1088-1094

Gesch, R.W., A. Royo-Esnal, E. Edo-Tena, J. Recasens, T.A. Isbell and F. Forcella, 2016. Growth environment but not seed position on the parent plant affects seed germination of two Thlaspi arvense L. populations. Indus. Crops Prod., 84: 241-247

Holubowicz, R., W. Xian and W. Siutaj, 2001. Use of tetrazolium (TTC), germ's and greenhouse plant emergences methods for testing seed vigour of selected ornamental plant species. Acta Agrobot., 54: 5-11

Kaldy, J.E., D.J. Shafer, M.S. Ailstock and A.D. Magoun, 2015. Effects of temperature, salinity and seed age on induction of Zostera japonica germination in North America, USA. Aquat. Bot., 126: 73-79
Li, L.Y., D. Zhan, Y.F. Wei, G.Y. Zhong, S.Y. Qin and B.Z. Cirewn, 2002. Conservation of endangered species resources of Tibetan medicine in China. Chin. J. Chin. Mater. Med., 27: 561-564

Ma, Y.H., F. Sun, J. Sun, G.S. Chen and W.H. Xu, 2005. Research advances in a Tibetan medicine-Gentiana straminea. J. Anhui Agric. Sci., 33: 1668-1677

Nabaei, M., P. Roshandel and A. Mohammadkhani, 2011. Effective techniques to break seed dormancy and stimulate seed germination in Rheum ribes L. Int. J. Oral Maxillofacial Surg., 44: 229

Niu, X.X., X.W. Chen, H. Su, A.E. Eneji, Y.H. Guo and X.H. Dong, 2014. Changes of secondary metabolites and trace elements in Gentiana macrophylla Flowers: A potential medicine plant part. Chin. Herb. (CHM), 6: 145-151

Seo, M., Y. Kanno, A. Frey, H.M. North and A. Marion-Poll, 2016 Dissection of Arabidopsis NCED9 promoter regulatory regions reveals a role for ABA synthesized in embryos in the regulation of GA-dependent seed germination. Plant Sci., 246: 91-97

Skryzypczak, L., M. Wesolowska and E. Skrzypczak, 1993. Gentiana species XII: In vitro culture, regeneration, and production of secoiridoid glucosides. In: Biotechnology in Agriculture and Forestry, Vol. 21. Bajaj, Y.P.S. (ed.). Medicinal and aromatic plants IV. Springer-Verlag: Berlin, Germany

Torra, J.A. Royo-Esnal and J. Recasens, 2015. Germination ecology of five arable Ranunculaceae species. Weed Res., 55: 503-513

Wang, P.C., M. Bentian, Z.F. Long, S.Q. Fan, H.H. Wang and L.B. Wang, 2016. Factors affecting seed germination and emergence of Sophora davidii. Ind. Crops Prod., 87: 261-265

Yu, F., F.Yu, R.Li and R. Wang, 2004. Inhibitory effects of the Gentiana macrophylla (Gentianaceae) extract on rheumatoid arthritis of rats. $J$. Ethnopharmacol., 95: 77-81

Zhao, Z.L., G. Dorje and Z.T. Wang, 2010. Identification of medicinal plants used as Tibetan traditional medicine Jie-Ji. J. Ethnopharmacol., 132: 122

(Received 01 August 2016; Accepted 28 February 2017) 